\title{
RELICÁRIO PROFISSIONAL: FEITIOS E MODOS DE FAZER A DOCÊNCIA EM UMA INSTITUIÇÃO ESCOLAR CONFESSIONAL CATÓLICA
}

RELICARIO PROFESIONAL: CARACTERÍSTICAS Y FORMAS DE TOMAR LA ENSEÑANZA EN UNA INSTITUCIÓN ESCOLAR CONFESIONAL CATÓLICA

\section{PROFESSIONAL RELIQUARY: WAYS AND MEANS OF TEACHING IN A CATHOLIC CONFESSIONAL SCHOOL}

\section{Marta Rochelly Ribeiro GONDINHO}

Universidade Federal do Piauí (UFPI), Teresina - PI - Brasil. Professora Adjunta do Departamento Métodos e Técnicas de Ensino - DMTE.

Doutorado em Educação (UFRJ).

ORCID: https://orcid.org/0000-0001-9726-2880.

E-mail: martarochelly81@ @otmail.com

Caio VELOSO

Universidade Federal do Piauí (UFPI), Teresina - PI - Brasil. Doutorando no Programa de Pós-Graduação em Educação (PPGEd/UFPI). ORCID: https://orcid.org/0000-0002-0397-0796. E-mail: $\underline{\text { caio.veloso@ifma.edu.br }}$

Viviane Ribeiro Rocha dos SANTOS Universidade do Minho (UMINHO), Braga - Portugal. Mestranda em Ciências da Educação. ORCID: https://orcid.org/0000-0002-8721-5869.

E-mail: vivi_rrsantos@hotmail.com 
GONDINHO, M. R. R.; VELOSO, C.; SANTOS, V. R. R.Relicário profissional: feitios e modos de fazer a docência em uma instituição escolar confessional católica. R. Científica UBM - Barra Mansa (RJ), ano XXVI, v. 23, n. 44, 1 . Sem. 2021 p. 72-89.

ISSN 1516-4071

\section{RESUMO}

O presente artigo inscrito nos estudos sobre a história da profissão docente assume a investigação sobre histórias de vida para pensar sobre os modos de constituir-se professor em diferentes cenários. Nesta pesquisa, investigou-se histórias de professoras em um espaço escolar confessional católico, cujo objetivo foi analisar os processos de constituição da identidade profissional de professores da escola confessional católica Irmã Maria Catarina Levrini, em Teresina-PI, de 1957 a 2003. Dialogou-se teoricamente com Caria (2008) e Nóvoa (1999) sobre histórias da profissão e a constituição da profissionalidade docente. Fez-se uso da história oral para a construção dos dados a partir da memória das informantes. Suas reminiscências foram categorizadas e analisadas à luz das discussões identitárias. Os achados da pesquisa sinalizaram que os espaços educativos, ao se institucionalizarem, circunscrevemse nas histórias dos sujeitos forjando um projeto de sociedade, especialmente nos sujeitos/professores e nas suas práticas profissionais, assim como os professores, ao exercerem sua ação profissional nas instituições, também deixam marcas singulares de sua ação.

Palavras-Chave: Profissão docente. Identidade docente. Escola confessional católica.

\section{RESUMEN}

Este artículo, inscrito en estudios sobre la historia de la profesión docente, asume la investigación de historias de vida para pensar las formas de convertirse en docente en diferentes escenarios. En esta investigación se investigaron historias de maestros en un espacio de escuela confesional católica, cuyo objetivo fue analizar los procesos de constitución de la identidad profesional de los maestros del colegio confesional católico Hermana María Catarina Levrini, en Teresina-PI, de 1957 a 2003. teóricamente con Caria (2008) y Nóvoa (1999) sobre los relatos de la profesión y la constitución de la profesionalidad docente. Se utilizó la historia oral para construir datos a partir de la memoria de los informantes. Sus reminiscencias fueron categorizadas y analizadas a la luz de discusiones sobre identidad. Los hallazgos de la investigación señalaron que los espacios educativos, al institucionalizarse, se circunscriben en los relatos de los sujetos que forjan un proyecto de sociedad, especialmente en los sujetos / docentes y en sus prácticas profesionales, así como los docentes, al ejercer su acción profesional en las instituciones.también dejan huellas únicas de su acción.

Palabras Clave: Profesión docente. Identidad docente. Escuela confesional católica.

\section{ABSTRACT}

This article, inscribed in studies on the history of the teaching profession, assumes the investigation of life stories to think about the ways of becoming a teacher in different scenarios. In this research, stories of teachers in a Catholic confessional school space were investigated. As an objective to analyze the processes of constitution of the professional identity of teachers of the Catholic confessional school Irmã Maria Catarina Levrini in Teresina-PI from 19572003. It was theoretically discussed with Caria (2008) and Nóvoa (1999) about stories of the profession and the constitution of teaching professionalism. Oral history methodology was used to build data from the informants' memory. Their reminiscences were categorized and analyzed in the light of identity discussions. The research findings signaled that the educational spaces, when institutionalized, are circumscribed in the stories of the subjects forging a project of society, especially in the subjects / teachers and in their professional practices, as well as the 
GONDINHO, M. R. R.; VELOSO, C.; SANTOS, V. R. R.Relicário profissional: feitios e modos de fazer a docência em uma instituição escolar confessional católica. R. Científica UBM - Barra Mansa (RJ), ano XXVI, v. 23, n. 44, 1 . Sem. 2021 p. 17-89.

ISSN 1516-4071

teachers when exercising their professional action in the institutions also leave singular marks of its action.

Keywords: Teaching profession. Teaching identity. Catholic confessional school.

\section{INTRODUÇÃO}

“A profissão docente conduz a uma cotidianidade invisível, uma vez que deve: estabelecer uma difícil convivência entre viver a realidade do que nos rodeia para introduzi-la nas lições e na vida das aulas de cada dia; recordar o passado para que as crianças e os adolescentes reconstruam e eduquem sua própria inteligência a partir do que foi criado; projetar-se ao futuro com a intencionalidade de que as novas gerações possam criar um mundo melhor para eles e para todos".

Francisco Imbernón

As questões norteadoras que provocaram o desejo de pesquisa neste estudo debruçaramse sobre os seguintes questionamentos: Como é constituída a identidade profissional de professores em contexto escolar confessional católico? Qual sua implicação na produção local da profissão docente? Tais questionamentos suscitaram, assim, a elaboração do seguinte objetivo: Analisar os processos de constituição da identidade profissional de professores da escola confessional católica Irmã Maria Catarina Levrini, em Teresina-PI, de 1957 a 2003. Metodologicamente, entrevistou-se cinco professoras que serão identificadas por Magister A, B, C, D e E, fazendo uso das contribuições da metodologia da história oral para análise das entrevistas concedidas.

A história da profissão docente é a história de professores em sua mais complexa relação com a sociedade, cultura, política e economia, bem como com as peculiaridades de sua experiência pessoal e sua singularidade. Seus tempos, suas histórias, suas memórias, suas reminiscências embasam, hoje, uma efervescente discussão em torno das identidades de professores. É sob a égide destas que se optou por pesquisar a história de professores no espaço escolar confessional católico.

Um espaço escolar confessional católico para estudar/investigar/pesquisar a identidade profissional de professores? Sim. Dos tantos modos de pensar a identidade para si (transação subjetiva - identidades herdadas e visadas) e para o outro (transação objetiva - identidades atribuídas e incorporadas), as nuances do espaço escolar aguçam curiosidades sobre seu papel desempenhado nesSa fabricação.

Diante de um contexto em que a profissão é forjada em dois grandes movimentos: de um lado, o projeto educativo intencionalmente confeccionado pelo Estado e, de outro, as ações 
GONDINHO, M. R. R.; VELOSO, C.; SANTOS, V. R. R.Relicário profissional: feitios e modos de fazer a

docência em uma instituição escolar confessional católica. R. Científica UBM - Barra Mansa (RJ), ano XXVI, v. 23, n. 44, 1 . Sem. 2021 p. 72-89.

ISSN 1516-4071

de reprodução e recriação dos modos de operacionalização do ensino elaborados pelos professores, um movimento antagônico de investimento e desinvestimento é apresentado aos principais interessados, que é a categoria profissional dos professores que, oficialmente, é responsável pelo projeto de transformação social de uma nação.

As atuais exigências impostas a essa categoria balizam a constituição das identidades profissionais e biográficas dos professores, uma vez que sendo a pessoa o professor e o professor a pessoa, essa dinâmica alterará o ciclo de vida destes. Uma das questões que pode evidenciar isto é o fato de a sobrecarga de trabalho do professor afetar diretamente a sua dinâmica pessoal chegando, em alguns casos, a provocar o seu adoecimento, o seu afastamento das atividades culturais e o desinteresse pelo investimento na formação continuada.

O lugar institucional desta pesquisa é a Escola Irmã Maria Catarina Levrini (E.I.M.C.L.), fundada em 14 de fevereiro de 1957, pertencente à Congregação religiosa das Irmãs pobres de Santa Catarina de Sena. O recorte temporal da pesquisa data da criação da escola até a data de comemoração do centenário da chegada das irmãs desta congregação em terras piauienses e também por demarcar a nova jurisprudência da escola. A escola Irmã Maria Catarina Levrini, instituição confessional católica, é o lócus desta pesquisa, que será entendida como fundo da investigação sobre professores. Os protagonistas do estudo são os professores, os aspectos políticos e institucionais que atravessaram a análise para dar conta do contexto em que são forjadas as constituições identitárias.

Para pensarmos este artigo, optamos por rememorar os modos de fazer e operacionalizar a docência no interior desta instituição escolar que confere marcas identitárias às professoras.

\section{DESENVOLVIMENTO}

\subsection{FEITIOS E MODOS DE FAZER A DOCÊNCIA EM UMA INSTITUIÇÃO ESCOLAR CONFESSIONAL CATÓLICA}

Em seus estudos sobre a epistemologia da cultura-conjuntura aplicada à análise das atividades de grupos de trabalho técnico-intelectual, Caria (2008) fez uso do conceito de cultura na investigação sobre as profissões. Especificamente, estudou sobre a cultura profissional de professores da educação básica em Portugal; em seu legado, evidenciou a dualidade de sentido existente entre o contexto da ação profissional docente e o contexto da ação política em educação. $\mathrm{O}$ autor registra que, 
GONDINHO, M. R. R.; VELOSO, C.; SANTOS, V. R. R.Relicário profissional: feitios e modos de fazer a docência em uma instituição escolar confessional católica. R. Científica UBM - Barra Mansa (RJ), ano XXVI, v. 23, n. 44, 1 . Sem. 2021 p. 17-89.

ISSN 1516-4071

[...] quanto ao fenômeno identitário, introduz-se uma outra delimitação: existe uma identificação do actor social com a atividade laboral que é principalmente determinada pela interacção social (presencial ou em rede) entre pares da mesma profissão e que por isso não se limita apenas à interpretação e interiorização pessoal do papel no quadro da instituição em que se trabalha ou à resistência e oposição a processos de racionalização técnico-burocrático das organizações. Há uma identificação do grupo profissional com a atividade sendo esta principalmente determinada pela subjetividade coletiva dos profissionais em causa inscrita (CARIA, 2007, p. 127).

Esta identificação do grupo com a atividade determinada pela subjetividade é situada pela adesão dos sujeitos ao projeto em que estes fazem parte ao realizarem sua atividade profissional. Pelas narrativas das cinco professoras, percebemos a identificação dos atores sociais em contextos de interação social:

Optei por trabalhar na E.I.M.C.L! Fiz dessa opção uma escolha de vida. Me envolvi de tal forma que a escola já me parecia familiar. Meus filhos, meus sobrinhos e meus vizinhos estudavam lá. Íamos juntos e voltávamos juntos, fizemos dos eventos da escola nossos momentos de interação e lazer cultural. (Trecho Magister A)

Sou bastante religiosa, este fato gerou em mim um sentimento de envolvimento maior com as causas das irmãs. Acredito na proposta da escola, sei o que ela significa e significou na vida de muitas famílias daquela região. Meu envolvimento se confirmava sempre que eu via as irmãs em oração pelo sucesso daquele projeto educativo e social. As irmãs são pessoas humildes e muito simples, porém bastante exigentes. Entendi essa exigência desde o dia em que a irmã Jacira falou: é porque a escola é para pobre que devemos fazer o nosso melhor, afinal, o pobre é o sacramento de Cristo, agradamos a Deus cuidando com excelência dos mais necessitados. Aprendi muitas lições. Levo estas lições para minha vida pessoal. (Trecho Magister C)

O nosso grupo de professores era bastante coeso, dificilmente convergíamos, não porque temíamos as irmãs que eram linha dura, mas porque corroborávamos com as propostas que geralmente era o reflexo das nossas necessidades coletivas. Tivemos momentos de discordância e até mesmo de desentendimentos entre nós professores e a administração escolar, mas nossa rede de apoio nos tranquilizava e não desistíamos. (Trecho Magister D)

A familiaridade, a interação, o sentimento de envolvimento, a credibilidade no projeto educativo e a rede de apoio dos professores mencionadas nas falas supracitadas das professoras A, C e D, confirmam a identificação dos atores sociais em uma perspectiva mais coletiva, como o preconizado por Caria (2008).

A identificação do ator social com a atividade laboral é determinada pela interação social. Para além dos espaços institucionais, existe uma noção de grupo que em cada professor se coletiviza. Diante da noção de grupo em que ele está inserido, esse propósito identificado nos faz pensar na atual dinâmica das ações coletivas dos professores. Mesmo com uma crescente especulação em torno do ato solitário de se constituir professor, não podemos deixar de percebê-lo enquanto grupo. 
GONDINHO, M. R. R.; VELOSO, C.; SANTOS, V. R. R.Relicário profissional: feitios e modos de fazer a docência em uma instituição escolar confessional católica. R. Científica UBM - Barra Mansa (RJ), ano XXVI, v. 23, n. 44, 1 . Sem. 2021 p. 72-89.

ISSN 1516-4071

Em seus estudos sobre a formação de professores, fez uso da conjugação dos elementos rigor teórico e conceitual da investigação em história associados ao engajamento relativo às causas da profissão professor (NÓVOA, 1999), para pensar na perspectiva da história comparada à construção de modelos de análise sobre os elementos que constituem a identidade profissional.

Usando as histórias de vida como ferramenta para analisar a constituição da prática educativa e dos saberes docentes, Nóvoa (1999) impulsionou reflexões importantes como: a história do ofício, o desenvolvimento da carreira, o engajamento profissional, a cultura profissional, os dispositivos de compreensão das relações de ensino e aprendizagem e o exercício coletivo da profissão. É notória a necessidade identificada em seus estudos de uma formação de professores construída dentro da profissão. Para a compreensão do processo histórico de profissionalização do professorado, o autor esboçou um modelo analítico em torno de quatro etapas: Exercício da atividade docente como ocupação principal; Licença oficial que legitima a condição de profissionais do ensino que funciona como controle do corpo docente; Formação profissional e Associações profissionais, que foram tomados como roteiro de investigação neste estudo, em parceria com os dispositivos analíticos discorridos dos estudos acima enunciados.

Para Jean-François Sirinelli (2006), o conceito de geração como uma peça importante da 'engrenagem do tempo' se constitui como uma escala móvel, o que limita certamente as virtudes da periodização, o que não a destitui de um elemento de análise fecundo para a história. Assim,

[...] a geração existe, portanto, no território do historiador, ao mesmo tempo como objeto de história e como instrumento de análise. Pode ser ela então um instrumento de medida do tempo? [...] Do que foi dito antes, destacaremos dois pontos. Por um lado, seguramente a geração padrão não existe: em nenhum caso podemos distinguir nela uma estrutura cronologicamente invariável, que transcende as épocas e os países. Por outro, e sem que haja contradição com a primeira observação, a geração é seguramente uma peça essencial da engrenagem do tempo, mas cuja importância pode variar conforme os setores estudados e os períodos abordados (SIRINELLI, 2006, p. 137).

Gerações de professores? Como é possível pensar em uma medida de tempo que agregue um grupo de profissionais? Que instrumentos de análise posso usar para pensar uma geração de professores ao longo de cinco décadas? Os aspectos normativos? Os aspectos institucionais? As práticas pedagógicas? Os sentidos atribuídos à docência?

Para Sirinelli (2006), não é possível padronizar gerações devido aos aspectos cronológicos transcenderem às épocas. Ela não pode ser uma medida de tempo, entretanto, por 
GONDINHO, M. R. R.; VELOSO, C.; SANTOS, V. R. R.Relicário profissional: feitios e modos de fazer a docência em uma instituição escolar confessional católica. R. Científica UBM - Barra Mansa (RJ), ano XXVI, v. 23, n. 44, 1 . Sem. 2021 p. 17-89.

ISSN 1516-4071

ser uma importante engrenagem do tempo, ela pode ser inventada e nos servir de objeto de análise de formas variadas, assumindo importâncias diversas, como podemos perceber na fala da professora A:

[...] nós, professores, temos muitas coisas em comum que nos aproximam. Não é a idade que nos faz parecidos, mas os contextos que atravessamos, as questões que vivemos juntas em cada tempo. Na escola, cada tempo é marcado por uma geração de professores que tinham coisas em comum, essas coisas a que me refiro é forma de ver o mundo, a aprendizagem, de se relacionar com os alunos e nossas práticas. (Trecho magister $\mathrm{A}$ )

O sentido de geração acolhido nesta pesquisa fora o preconizado por Sirinelli (2006), que afirma que o uso do conceito de geração está alicerçado no sentido histórico, reflexo da inserção do homem na profundidade histórica, que remete a ideia de uma modalidade específica do viver e do pensar e de intervenção no processo histórico. Para justificar a expressão geração, ressalto a existência de um campo de debates que a questiona no sentido historiográfico, no seu sentido polêmico da periodização e ainda no seu sentido biológico. Entretanto, segundo o autor supracitado:

\footnotetext{
Caberia então negar a geração qualquer virtude periodizante? Isso seria um equívoco, pois a geração é de fato uma peça importante da engrenagem do tempo e como tal deve ser tratada, como a condição, todavia desde logo dois limites desse padrão (SIRINELLI, 2006, p. 134).
}

Assim, sugere o entendimento de que o termo geração é elástico "devendo-se banir qualquer visão pitagórica das gerações”, entendendo-a como uma escala móvel do tempo. Estas gerações de professoras incorporaram modos de viver e fabricar a docência ao longo de suas trajetórias neste espaço institucional.

Nos quadros seguintes, foram selecionados pontos de reflexões presentes nas narrativas das professoras sobre seus feitos e modos de vivenciar a docência no interior da E.I.M.C.L.

As impressões tecidas sobre a ação de trabalhar em uma escola confessional católica (Quadro 01) nos remetem aos sentidos atribuídos pelas professoras às suas experiências profissionais no interior de um espaço escolar. Identificamos a expressão 'tarefa' nos argumentos apresentados por três das cinco professoras. Esse entendimento é atribuído à dimensão educativa e religiosa, dessa forma, é praticamente consensual entre elas que o desempenho das atividades docentes está circunscrito em um imaginário social que reconhece as especificidades do projeto educativo de um espaço confessional. Essa construção de imaginário tem implicações diretas sobre o trabalho que elas realizam, sobre as convicções que orientam o trabalho e, sobretudo, em relação aos sentidos atribuídos às suas práticas 
GONDINHO, M. R. R.; VELOSO, C.; SANTOS, V. R. R.Relicário profissional: feitios e modos de fazer a docência em uma instituição escolar confessional católica. R. Científica UBM - Barra Mansa (RJ), ano XXVI, v. 23, n. 44, 1 . Sem. 2021 p. 72-89.

ISSN 1516-4071

pedagógicas. No plano identitário, essa experiência constrói os indivíduos e definem as instituições (DUBAR, 2005).

Quadro 1 - Trabalhar em uma escola confessional católica

\begin{tabular}{|c|c|}
\hline PROFESSORAS & REMINISCENCIAS/FEITIOS \\
\hline MAGISTER A & Tarefa educativa e social \\
\hline MAGISTER B & Um privilégio profissional \\
\hline MAGISTER C & Tarefa cristã e também educativa \\
\hline MAGISTER D & Cobranças \\
\hline MAGISTER E & Tarefa educativa com fortes fundamentos \\
& religiosos. \\
\hline
\end{tabular}

Fonte: Elaborado pelos autores

Uma vez incorporados os valores religiosos com elementos distintivos da tarefa educativa e do trabalho pedagógico realizado pela escola, as professoras operacionalizam atividades com cunho confessional e criam modos de vivenciar as práticas valorativas que professam a fé cristã no calendário das atividades programadas que são distribuídas durante o ano escolar. O projeto educativo é posto em prática nesta dimensão curricular.

A prática pedagógica do professor tem enfoques claramente definidos quanto aos seus objetivos religiosos. Assim,

[...] as escolas confessionais, ao contrário das escolas laicas, definem como objetivo primacial de sua prática pedagógica o desenvolvimento de uma opção religiosa e a adoção de uma conduta moral em seus alunos; para atingir essa meta, a escola confessional dissemina os conhecimentos filosóficos-teológicos e os princípios educacionais da ordem religiosa à qual se vincula (BITTAR, 1999, p. 127).

As professoras, ao pensarem sobre si enquanto profissionais, acionam uma memória educativa repleta de sentidos sobre a dialética da relação com a escola, com o conhecimento, com os sujeitos e com a vida. As escolas confessionais católicas, segundo as professoras, têm suas singularidades. Ao comparar o trabalho realizado nestes espaços com o trabalho realizado em escolas públicas, estas enfatizaram que:

O que a escola tinha de diferente da escola pública era uma cultura voltada para as coisas acontecerem, para as coisas darem certo. Na escola pública, a impressão que me dá é que, em qualquer que seja o tempo, funcionários não se envolvem com a causa. A clientela do Catarina eram crianças pobres igualmente às da escola pública, mas a administração escolar das irmãs prezava pela excelência de tal forma que os espaços se tornam distintos. A grande lógica era de melhorar a vida 
GONDINHO, M. R. R.; VELOSO, C.; SANTOS, V. R. R.Relicário profissional: feitios e modos de fazer a docência em uma instituição escolar confessional católica. R. Científica UBM - Barra Mansa (RJ), ano XXVI, v. 23, n. 44, 1 . Sem. 2021 p. 17-89.

ISSN 1516-4071

dos alunos pela escolarização ou, como as irmãs diziam, para saída da condição de miséria intelectual e da ignorância. Na E.I.M.C.L. éramos envolvidas com a causa dos mais pobres, buscando o melhoramento via projeto educativo. (Trecho Magister A)

Na escola pública, os professores passam é de um mês inteiro de greve e nem se preocupam com os alunos. Na E.I.M.C.L. não entrávamos em greve de jeito nenhum, porque pensávamos nas centenas das crianças que ali estavam para se alimentar, tanto de comida como de conhecimento. (Trecho Magister C)

É interessante que todas as professoras queriam seus filhos estudando na E.I.M.C.L, mas não queriam estudando na escola pública. Ora, se as professoras fazem essa opção é porque sabem que a escola confessional é melhor, independente se é porque ali é o seu lugar de trabalho, matriculamos nossos filhos onde confiamos. (Trecho Magister D)

Nas três falas das professoras, embora com questões distintas, existe um ponto em comum que é a comparação entre os espaços confessionais e os espaços públicos de ensino. Um ponto salutar é que ambos os espaços são lócus de trabalho das mesmas professoras, que têm posicionamentos distintos sobre eles. A professora A destaca uma cultura amparada na eficácia escolar e no papel dos sujeitos como distintivos de sucesso escolar. Ela atribui à incorporação da causa do projeto educativo como uma tomada de decisão fortemente influenciada pela cultura da administração escolar quando esta trabalha exigindo qualidade.

A professora $\mathrm{C}$ usou o movimento grevista para pensar as posturas institucionais; ela justifica social e ideologicamente a tomada de decisão por se abster da greve em virtude do compromisso social com os alunos em detrimento do compromisso com a melhoria da profissão e da educação de nosso país. Por fim, a Professora D enfatizou a comparação da procura pelas escolas confessionais em detrimento da escola pública sob a simples justificativa de que a escola confessional seria uma escola de melhor qualidade.

O panorama comparativo em tela evidencia pontos que nos fazem pensar sobre o lugar institucional de uma escola confessional católica na trajetória profissional de professoras ao longo de algumas décadas, afinal, estes espaços conformam repertórios que a distinguirão de outros funcionários públicos. Assim, esses espaços influenciam diretamente na constituição de um habitus docente.

Em questões alusivas às especificidades do trabalho em escolas confessionais (Quadro 02), consensualmente, as professoras A, B, C e D enfatizaram que os rituais caracterizam esse trabalho. $\mathrm{O}$ tratamento às questões religiosas tem lugar privilegiado no currículo formal e oculto da escola. Estas balizam interpretações valorativas e impulsionam a constituição de um corpo disciplinar no interior das aprendizagens e construção das experiências escolares. A professora E apontou os mecanismos disciplinares e suas mediações como uma marca significativa dos trabalhos em espaços escolares confessionais, uma vez que estes carregam marcas punitivas de 
GONDINHO, M. R. R.; VELOSO, C.; SANTOS, V. R. R.Relicário profissional: feitios e modos de fazer a docência em uma instituição escolar confessional católica. R. Científica UBM - Barra Mansa (RJ), ano XXVI, v. 23, n. 44, 1 . Sem. 2021 p. $72-89$.

ISSN 1516-4071

controle pela simples obediência a um conjunto de dispositivos organizados entre o que é permitido e proibido perante a lei de Deus e dos homens.

Quadro 2 - Especificidade de trabalho em escolas confessionais católicas

\begin{tabular}{|c|c|}
\hline PROFESSORAS & REMINISC $\hat{E N C I A S / F E I T I O S ~}$ \\
\hline MAGISTER A & Rituais \\
\hline MAGISTER B & Rituais \\
\hline MAGISTER C & Rituais \\
\hline MAGISTER D & Rituais \\
\hline MAGISTER E & Mediações com a indisciplina e a disciplina. \\
\hline
\end{tabular}

Fonte: Elaborado pelos autores

Esses dispositivos disciplinares são construídos pela doutrina apresentada diariamente, a partir dos rituais de rotina, do currículo operacionalizado, bem como dos eventos que agregam a escola em torno de um objetivo comum e que reproduzem a ideologia cristã.

No tocante à escola e à rotina do trabalho docente, todas as professoras deram um destaque quantitativo ao volume de trabalho, expressões como muito trabalho se repetiram nas falas das professoras B, D e E. Nas falas das professoras A e C, receberam outro tratamento: intenso e desgastante, ambas evidenciaram as queixas quanto ao acúmulo de tarefas muito presentes nos discursos de professores que trabalham na rede privada de ensino e também na rede pública. A rotina excessiva de trabalho está circunscrita, especialmente na atualidade, nos discursos de precarização do trabalho docente, razão pelo qual se torna evidente o desestímulo e o abandono da carreira logo nos primeiros anos da docência.

A identidade nunca é instalada, nunca é acabada. Os indivíduos passam por crises de identidade, Dubar (2005) afirma. Especificamente, as condições de trabalho acentuam as crises de identidade na docência em relação a aspectos como desvalorização do magistério, as condições materiais de trabalho, ao plano de cargos e salários e a dinâmica de trabalho coletivo que envolve a cultura organizacional.

Quadro 3 - A escola (E.I.M.C.L.) e a rotina de trabalho docente

\begin{tabular}{|c|c|}
\hline PROFESSORAS & REMINISC $\hat{E N C I A S / F E I T I O S ~}$ \\
\hline MAGISTER A & Intensa \\
\hline MAGISTER B & Muito trabalho \\
\hline MAGISTER C & Apesar das rotinas diárias serem desgastantes, cada \\
& dinico \\
\hline
\end{tabular}


GONDINHO, M. R. R.; VELOSO, C.; SANTOS, V. R. R.Relicário profissional: feitios e modos de fazer a docência em uma instituição escolar confessional católica. R. Científica UBM - Barra Mansa (RJ), ano XXVI, v. 23, n. 44, 1 . Sem. 2021 p. 17-89.

\begin{tabular}{|c|c|}
\hline MAGISTER D & Dinâmica e de muito trabalho \\
\hline MAGISTER E & Muito trabalho. \\
\hline
\end{tabular}

Fonte: Elaborado pelos autores

As rotinas escolares são bastante específicas e têm uma relação direta com seu projeto pedagógico. A E.I.M.C.L. tem um calendário de eventos inserido em seu Projeto Político Pedagógico baseado nas festividades cristãs, datas cívicas nacionais e locais que demandam do seu pessoal docente um alto grau de preparação e envolvimento para além das atribuições pedagógicas em sala de aula. Tais rituais enfatizam o projeto educativo curricular da escola e evidenciam os posicionamentos dos professores frente à manutenção ou transformação destes.

No tocante à percepção pessoal sobre ser professor na E.I.M.C.L. (Quadro 04), questões como o grau de satisfação, o envolvimento, o reconhecimento das aprendizagens coletivas e a familiaridade são elementos de afinidade identitária das professoras com o projeto institucional escolar no qual fazem parte. Existe uma adesão reconhecida com argumentos como o emitido pela professora B e um entendimento formativo, como a fala da professora $\mathrm{E}$.

Quadro 4 - Percepção Pessoal: ser professor na E.I.M.C.L.

\begin{tabular}{|c|c|}
\hline PROFESSORAS & REMINISCENCIAS/FEITIOS \\
\hline MAGISTER A & $\begin{array}{c}\text { "Sou satisfeita de ter sido professora do Catarina } \\
\text { durante tantos anos, praticamente só lá. Abdiquei de muitas } \\
\text { coisas, mas valeu à pena" }\end{array}$ \\
\hline MAGISTER B & $\begin{array}{r}\text { "As colegas que eram do estado e trabalhavam em } \\
\text { escolas do estado diziam que eu era boba, escrava das } \\
\text { irmãs. Eu não ligava!" }\end{array}$ \\
\hline MAGISTER C & "São muitas histórias, muito envolvimento. O \\
& Catarina é minha casa, minha família em profissão e em \\
& cristo"
\end{tabular}

Fonte: Elaborado pelos autores

A afinidade identitária é o que nos toca ao manusear um álbum de fotografias presente no arquivo escolar em que percebemos a expressão artística dos rituais de propagação da fé 
GONDINHO, M. R. R.; VELOSO, C.; SANTOS, V. R. R.Relicário profissional: feitios e modos de fazer a docência em uma instituição escolar confessional católica. R. Científica UBM - Barra Mansa (RJ), ano XXVI, v. 23, n. 44, 1 . Sem. 2021 p. $72-89$.

ISSN 1516-4071

cristã paralela ao envolvimento descrito pelas professoras ao realizarem as atividades culturais de forma planejada, combinada e com muita sensibilidade.

Quadro 5 - Percepção Profissional: ser professor na E.I.M.C.L.

\begin{tabular}{|c|c|}
\hline PROFESSORAS & REMINISCÊNCIAS/FEITIOS \\
\hline MAGISTER A & $\begin{array}{l}\text { Ter espiritualidade e assumir o compromisso de } \\
\text { educar crianças em suas diversidades }\end{array}$ \\
\hline MAGISTER B & Ser exemplo de profissional \\
\hline MAGISTER C & $\begin{array}{l}\text { Significa que assumimos o compromisso para além } \\
\text { de educar, instruir para o bem }\end{array}$ \\
\hline MAGISTER D & $\begin{array}{l}\text { Desenvolver um bom trabalho e estimular a } \\
\text { preparação para a vida }\end{array}$ \\
\hline MAGISTER E & $\begin{array}{l}\text { Além da realização de um trabalho compete um } \\
\text { cuidado ético com os alunos e a comunidade escolar. }\end{array}$ \\
\hline
\end{tabular}

Fonte: Elaborado pelos autores

Na percepção profissional sobre ser professor da E.I.M.C.L. (Quadro 05), o destaque das narrativas das professoras para aspectos do campo subjetivo como a espiritualidade, a instrução para o bem, ser exemplo e estimular a preparação para a vida, caracterizam o imaginário docente sobre a representação do professor no interior de uma escola católica filantrópica. Aspectos como o compromisso foram evidenciados nas falas das professoras A, C e E como uma dimensão ética do saber ser do professor. A percepção profissional sob a égide das falas das professoras interliga seus saberes de ordem conceitual com os saberes de ordem pessoal/cultural.

Quadro 6 - Significado da Escola para a bairro

\begin{tabular}{|c|c|}
\hline PROFESSORAS & REMINISCÊNCIAS/FEITIOS \\
\hline MAGISTER A & Oferta de educação de qualidade \\
\hline MAGISTER B & Formação para as crianças e para as famílias \\
\hline MAGISTER C & Escola boa, alunos mais preparados para o mercado \\
& de trabalho \\
\hline MAGISTER D & Crianças com melhores oportunidades de estudo em \\
& uma boa escola \\
\hline MAGISTER E & Melhoria de vários aspectos: éticos, religiosos e \\
& cognitivos. \\
\hline
\end{tabular}

Fonte: Elaborado pelos autores 
GONDINHO, M. R. R.; VELOSO, C.; SANTOS, V. R. R.Relicário profissional: feitios e modos de fazer a docência em uma instituição escolar confessional católica. R. Científica UBM - Barra Mansa (RJ), ano XXVI, v. 23, n. 44, 1 . Sem. 2021 p. 17-89.

ISSN 1516-4071

A escola significa para o bairro aprendizagem, sociabilidade e formação, uma vez que ela potencializa as oportunidades educacionais e constroem, enquanto práticas sociais, um repertório cultural de melhoramento das condições de pobreza no qual estão imersos. Para as professoras, a oferta de uma educação de qualidade legitima um status da escola em detrimento às demais do entorno, gerando uma concorrência entre os setores que atendem às camadas mais populares, como as escolas públicas e filantrópicas, e reconhecendo, nesta perspectiva, a competência das escolas confessionais filantrópicas por sua estratégia de melhoramento da qualidade da aprendizagem dos alunos, o que diretamente correlaciona a qualidade do ensino com a qualidade do trabalho realizado pelas professoras. Assim, a comunidade reconhece o trabalho desenvolvido pelas professoras conferindo a elas o adjetivo de competentes no exercício de sua função.

As escolas confessionais católicas em seu projeto pedagógico são fiéis divulgadoras da fé e da moral cristã. A crença de que elas tanto formavam uma elite cultural-intelectual bem sucedida, como é o caso das escolas de elite, como formavam a pobreza instruída na recusa da ignorância, como é o caso das escolas filantrópicas, são elementos que fizeram efervescer o reconhecimento de suas práticas educativas junto à sociedade e junto aos professores que faziam parte desta empreitada. Ideologicamente, os professores eram os sujeitos direitos da propagação deste propósito, uma vez que a escola é entendida como espaço efetivo e legítimo da conformação de crenças e valores em uma perspectiva tanto individual como coletiva.

Quadro 7 - Significado do trabalho dos professores para a comunidade local

\begin{tabular}{|c|c|}
\hline PROFESSORAS & REMINISC $\hat{E N C I A S / F E I T I O S ~}$ \\
\hline MAGISTER A & Melhoramento da qualidade da aprendizagem \\
\hline MAGISTER B & Preparação de cidadãos \\
\hline MAGISTER C & Formação cristã e educacional \\
\hline MAGISTER D & Preparação para o ensino superior \\
\hline MAGISTER E & Formação para vida. \\
\hline
\end{tabular}

Fonte: Elaborado pelos autores 
GONDINHO, M. R. R.; VELOSO, C.; SANTOS, V. R. R.Relicário profissional: feitios e modos de fazer a docência em uma instituição escolar confessional católica. R. Científica UBM - Barra Mansa (RJ), ano XXVI, v. 23, n. 44, 1 . Sem. 2021 p. $72-89$.

ISSN 1516-4071

O significado do trabalho dos professores para a comunidade local (Quadro 07) é reconhecido pela maioria dos membros da comunidade e associado ao trabalho social desenvolvido por estas, tanto na escola como na comunidade. Segundo Bittar (1999, p. 138):

Caracteriza-se como uma instituição de educação que presta serviços educacionais e/ou de assistência social, colocando-os à disposição da população sem exigir por eles qualquer tipo de remuneração. Em geral, esses serviços prestados pelas escolas filantrópicas são caracterizados como atividades complementares à ação do Estado; por essa razão, podem ser entendidas como medidas compensatórias, mas necessárias, para assegurar o acesso da população a determinados serviços.

Quadro 8 - Atos da atribuição: que tipo de professor você é?

\begin{tabular}{|c|c|}
\hline PROFESSORAS & REMINISC $\hat{E}$ NCIAS/FEITIOS \\
\hline MAGISTER A & $\begin{array}{c}\text { Responsável no desempenho das minhas } \\
\text { obrigações }\end{array}$ \\
\hline MAGISTER B & Disciplina e organizada \\
\hline MAGISTER C & Cuidadosa com as relações entre colegas e alunos \\
\hline MAGISTER D & Responsável \\
\hline MAGISTER E & Ética e comprometida com o desempenho das \\
& atividades pedagógicas. \\
\hline
\end{tabular}

Fonte: Elaborado pelos autores

A identidade para si (o que o indivíduo diz de si mesmo), para Dubar (2005), também entendido como processos biográficos, faz parte da estruturação identitária.

Quadro 9 - Atos de atribuição: o que dizem sobre você como professor?

\begin{tabular}{|c|c|}
\hline PROFESSORAS & REMINISC $\hat{E N C I A S / F E I T I O S ~}$ \\
\hline MAGISTER A & Lutadora, determinada e comprometida \\
\hline MAGISTER B & Que sou muito responsável \\
\hline MAGISTER C & Comprometida e ética \\
\hline MAGISTER D & Que sou perfeccionista e criativa \\
\hline MAGISTER E & Criativa e demonstro gostar muito do que faço. \\
\hline
\end{tabular}

Fonte: Elaborado pelos autores

Cada um pode recusar a identidade dada pelo outro e se definir de outra forma. A identidade é reivindicada pelo indivíduo. Segundo Dubar (2005, p. 135), 
GONDINHO, M. R. R.; VELOSO, C.; SANTOS, V. R. R.Relicário profissional: feitios e modos de fazer a docência em uma instituição escolar confessional católica. R. Científica UBM - Barra Mansa (RJ), ano XXVI, v. 23, n. 44, 1 . Sem. 2021 p. 17-89.

ISSN 1516-4071

Eu nunca posso ter certeza de que minha identidade para mim mesmo coincide com minha identidade para o outro. A identidade nunca é dada, ela sempre é construída e deverá ser (re)construída em uma incerteza maior ou menor e mais ou menos duradoura.

Quadro 10 - Atos de pertencimento: Que tipo de professor você quer ser?

\begin{tabular}{|c|c|}
\hline PROFESSORAS & REMINISCENCIAS/FEITIOS \\
\hline MAGISTER A & $\begin{array}{c}\text { Aquele que sempre aprende, que se renova e está } \\
\text { sempre atualizado }\end{array}$ \\
\hline MAGISTER B & Que se qualifica e que está motivado \\
\hline MAGISTER C & Aquele que não desiste dos que mais necessitam \\
\hline MAGISTER D & Que é ético nas tomadas de decisões \\
\hline MAGISTER E & $\begin{array}{c}\text { Em constante aprendizagem e que melhora a } \\
\text { qualidade do trabalho que faz. }\end{array}$ \\
\hline
\end{tabular}

Fonte: Elaborado pelos autores

Os feitios e modos de fazer e operacionalizar a docência no interior da instituição escolar nos impulsionou às seguintes constatações: a montagem de um grupo profissional para atuar nestas escolas congrega valores, regras e comportamentos que tanto atravessam a vida pessoal como a vida profissional dos sujeitos envolvidos.

Os estabelecimentos de ensino católicos podem ser definidos como espaços de disseminação de valores, comportamentos e atitudes. No seu interior, os feitios diários nos desvelam a constituição de esquemas de disposições duráveis, o seu trabalho instiga a formação de certo tipo de habitus por parte especificamente do seu grupo profissional de trabalho que age como propagador institucional de tais preceitos.

Pode-se fazer do habitus não o produto de uma condição social de origem, mas o de uma trajetória social definida com base em várias gerações e, mais precisamente da inclinação da trajetória social da descendência (BOURDIEU, 1974, p. 5).

No interior das escolas confessionais, seus feitios representam a reprodução e a produção dos comportamentos valorativos substanciados na fé cristã, desvelando por estes um projeto de civilidade e propagando um ideal pedagógico.

Estes espaços educativos fazem uso de arrojadas estratégias de socialização preconizadas pelos seus rituais, pelos seus momentos formativos, momentos assistencialistas 
GONDINHO, M. R. R.; VELOSO, C.; SANTOS, V. R. R.Relicário profissional: feitios e modos de fazer a docência em uma instituição escolar confessional católica. R. Científica UBM - Barra Mansa (RJ), ano XXVI, v. 23, n.

$$
\text { 44, 1. Sem. } 2021 \text { p. } 72-89 .
$$

ISSN 1516-4071

direcionados aos mais necessitados e pela divulgação do seu projeto através de sua equipe de trabalho para legitimar suas práticas e seu reconhecimento social amparado sob a égide religiosa.

Circunscritos na ideia de que a educação é a condição de elevação valorativa, os preceitos da fé cristã alicerceiam suas ações pedagógicas. As escolas confessionais, sendo representantes de uma ordem religiosa, serão entendidas pelos pares como um importante mecanismo capaz de influenciar a sociedade.

A formação de uma geração de alunos e professores submetidos a mecanismos diários de inculcação que induzem a modos de percepção do mundo é identificada a partir das estratégias de socialização que transformam estes espaços escolares em competentes lugares de fabricação de sociabilidades.

As identidades e suas eventuais cisões são produtos de uma tensão ou de uma contradição interna ao próprio mundo social (entre a ação instrumental e comunicativa, a societária e a comunitária, a econômica e a cultural, e não essencialmente como resultados do funcionamento psíquico e de seus recalques inconscientes (DUBAR, 2005, p. 137).

A produção e gestão das identidades profissionais de professores no interior de escolas confessionais católicas simbolizam uma rede de sociabilidades negociadas, apropriadas ou simplesmente incorporadas de uma série de capitais acionados nas práticas sutis e autoritárias da igreja católica manifestadas por suas congregações religiosas que comandam espaços escolares. Os feitios diários são imbricados de marcas que vislumbram a manutenção de um saber de antemão religioso que norteia as práticas educativas. Reforça-se, nesta dimensão, que a identidade

[...] refere-se a um conjunto de características, experiências e posições de sujeito atribuídas (e autoatribuídas) por diferentes discursos e agentes sociais aos docentes no exercício de suas funções, em instituições educacionais mais ou menos complexas e burocráticas. 1. Ainda que o termo identidade, do ponto de vista etimológico (qualidade "do mesmo", "de idêntico") e histórico-filosófico, remeta a uma perspectiva essencialista e unitária da identidade, o significado atual do termo no campo dos Estudos Culturais e em boa parte do pensamento sociológico contemporâneo ressalta o caráter construcionista das identidades. A identidade docente é, ao mesmo tempo, um processo de identificação e diferenciação, não fixo e provisório, que resulta de negociações de ordem simbólica que os professores realizam em meio a um conjunto de variáveis como suas biografias, as relações e condições de trabalho, a história e a cultura que caracteriza a docência enquanto atividade profissional, e representações colocadas em circulação por discursos que disputam os modos de ser e agir dos docentes no exercício do ensino e do trabalho docente (GARCIA, 2005, p. 51).

Destarte, a escuta e análise das narrativas das professoras se aproximam das contribuições supracitadas no que se refere à docência como elemento identitário que assume 
GONDINHO, M. R. R.; VELOSO, C.; SANTOS, V. R. R.Relicário profissional: feitios e modos de fazer a docência em uma instituição escolar confessional católica. R. Científica UBM - Barra Mansa (RJ), ano XXVI, v. 23, n. 44, 1 . Sem. 2021 p. 17-89.

ISSN 1516-4071

características, experiências e posições atribuídas, resultado de negociações cotidianas ligadas a fatores como legislação, expectativas sociais, relações e condições de trabalho com suas interfaces frente a cultura e demandas sociais de um tempo.

\section{CONSIDERAÇÕES FINAIS}

Considerando a proposta de analisar os processos de constituição da identidade profissional de professores da escola confessional católica Irmã Maria Catarina Levrini, em Teresina-PI, de 1957 a 2003, podemos concluir que ser professor das escolas confessionais católicas fora uma opção profissional para a vida. As professoras que participaram desta pesquisa têm em comum seus trajetos consolidados neste espaço, o que nos levou a perceber as marcas ideológicas das relações religiosas na conformação de um corpo de conhecimentos valorativos e pedagógicos que se circunscreveram de tal forma que os discursos da fé e da caridade se sobrepuseram ao profissional em muitos momentos no decorrer desta história. Ao longo de suas trajetórias profissionais, percebemos as marcas da religiosidade e que seus feitios se encontravam em sintonia com as propostas institucionais.

As professoras também inventaram modos/estratégias/táticas de convivência criativa ao longo destes percursos que simbolizaram uma vida em que tanto as professoras foram transformadas pela instituição, como elas transformaram a instituição.

\section{REFERÊNCIAS}

AMADO, J.; FERREIRA, M. M. (Coord.). Usos \& abusos da história oral. Rio de Janeiro: FGV, 2005.

AZZI, R. O catolicismo popular no Brasil. Petrópolis: Vozes, 1979.

BITTAR, M. Universidade comunitária: uma identidade em construção. Orientador: Bruno Pucci. 1999. 252 f. Tese (Doutorado em Educação) - Universidade Federal de São Carlos, São Carlos, 1999. Disponível em: https://docplayer.com.br/5142974-Universidade-comunitariauma-identidade-em-construcao.html. Acesso em: 6 nov. 2020.

BOURDIEU, P. A miséria do mundo. Petrópolis: Vozes, 1998.

BOURDIEU, P. A produção da crença: contribuição para uma economia dos bens simbólicos. São Paulo: Zouk, 2004. 
GONDINHO, M. R. R.; VELOSO, C.; SANTOS, V. R. R.Relicário profissional: feitios e modos de fazer a docência em uma instituição escolar confessional católica. R. Científica UBM - Barra Mansa (RJ), ano XXVI, v. 23, n. 44, 1 . Sem. 2021 p. $72-89$.

ISSN 1516-4071

BOURDIEU, P. Esboço de uma teoria da prática. In: Renato Ortiz (Org). Pierre Bourdieu. São Paulo: Ática, 1994.

BOURDIEU, P. O poder simbólico. 2. ed. Rio de Janeiro: Bertrand Brasil, 1998.

CARIA, T. H. A cultura profissional do professor de ensino básico em Portugal: uma linha de investigação a desenvolver. Sísifo: Revista de Ciências da Educação, Lisboa (Portugal), n. 3, p. 125-138, maio/ago. 2007.

DUBAR, C. A socialização: construção das identidades sociais e profissionais. Trad. Andréa Stahel M. da Silva. São Paulo: Martins Fontes, 2005.

GARCIA, M.; HYPOLITO, A.; VIEIRA, J. As identidades docentes como fabricação da docência. Educação e Pesquisa, São Paulo, v. 31, n. 1, p. 45-56, jan./abr. 2005.

NÓVOA, A. (Org.). Vidas de professores. 2. ed. Porto: LDA, 1995.

NÓVOA, A. Profissão professor: identidade e profissionalização docente. Brasília: Plano, 2002.

SIRINELLI, J. A geração. In: AMADO, J.; FERREIRA, M. M. Usos e abusos da história oral. Rio de Janeiro: Fundação Getúlio Vargas Editora, 1996. 